\title{
Instability of Chimaeric Antibody Secretion by Anti-Carcinoembryonic Antigen Producing Hybridoma Cells after Gene Targeting
}

\author{
Abir A. El-Abdallah ${ }^{\mathrm{a}}$ Christopher H.J. Ford ${ }^{\mathrm{b}}$ \\ Departments of a Pathology and ${ }^{b}$ Surgery, Faculty of Medicine, Kuwait University, Kuwait
}

\author{
Key Words \\ Chimaeric antibody $\cdot$ Gene targeting $\cdot$ Homologous \\ recombination
}

\begin{abstract}
Objective: To produce a chimaeric version of the 11-28514 anti-carcinoembryonic antigen (CEA) monoclonal antibody using a gene targeting approach. Materials and Methods: A replacement vector was constructed to insert the human constant $\gamma 1$ gene within the mouse heavy chain locus of 11-285-14 hybridoma cells. The mouse constant $\gamma 1$ gene $(1.5 \mathrm{~kb})$ and the mouse $\mu$ intron fragment $(2.2 \mathrm{~kb})$ were amplified by PCR and cloned into a pKO Scrambler vector. The human constant $\gamma 1$ gene fragment $(2.2 \mathrm{~kb})$ was cloned next to the intron fragment. Resistant colonies were screened by ELISA for the presence of the human isotype in their supernatants. Results: Of the 4,370 resistant colonies obtained, 87 colonies showed secretion of the human isotype at levels between 4 and $32 \mathrm{ng} / \mathrm{ml}$. PCR and Southern blot results confirmed the correct integration of the human gene by homologous recombination within the heavy chain locus. Most of the producers ceased to express the human isotype within a few weeks after the initial positive ELISA results. Instability of secretion could not be explained by genetic instability in all the clones, which suggests the presence of other undefined epigenetic or physiologic
\end{abstract}

mechanisms. Conclusion: Gene targeting resulted in transformants with unstable and low production rates of chimaeric anti-CEA antibody.

Copyright (C) 2005 S. Karger AG, Basel

\section{Introduction}

Therapeutic monoclonal antibodies (mAbs) have established themselves as important additional tools in the management of many diseases including cancer. Many mAbs are FDA approved for human use [1]; half of them are humanized by chimaerization (fusion of the variable region of the mouse $\mathrm{mAb}$ and the constant region of a human antibody). Clinical trials with chimaeric antibodies have shown that they are successful therapeutic agents because the insertion of human constant regions improves interaction with human $\mathrm{Fc}$ receptors, reduces immunogenicity and extends the metabolic survival of the therapeutic antibody [2].

$11-285-14$ is a mouse anti-human carcinoembryonic antigen (CEA) antibody of the immunoglobulin G1 (IgG1) isotype. This antibody has high specificity to CEA and does not cross-react with non-specific cross-reacting antigen. 11-285-24 and its derivatives have shown promising therapeutic effects with CEA expressing tumours in vitro and in preclinical models in vivo [3-5]. Significant differences exist in the ability of therapeutic antibodies 
to kill cancer cells even when these antibodies recognize the same antigen. These differences cannot be identified without extensive in vivo evaluation [1]. This is hampered mainly by the development of human anti-mouse antibodies (HAMAs) following repeated administration of antibody, which can cause deleterious effects to the patient and interfere with the therapeutic activity of the antibody. HAMAs are directed mainly against the Fc portion of the therapeutic antibody. Studies have shown that HAMA responses are greater and faster to whole Ig than to the divalent or monovalent fragments, consistent with the concept that the presence of the Fc portion increases the immunogenicity of Ig [2]. For 11-285-14 to be preclinically evaluated, a less immunogenic version is needed. Hence, the objective of this study was to produce a chimaeric version of 11-285-14 antibody by gene targeting the Ig heavy chain locus of the 11-285-14 hybridoma cells and inserting the human constant gene therein.

The choice of a gene targeting approach was based on the concept that homologous recombination allows the introduced human $\gamma 1$ gene to be expressed in a normal chromosomal context within the mouse heavy chain locus. The anticipated advantage of this approach was the stable and the high Ig expression reported to be obtained from targeted hybridomas [6]. If this could be accomplished, the problem of insufficient chimaeric antibody production rates and instability often seen in conventional transfectomas would be circumvented [7].

\section{Materials and Methods}

\section{Construction of Targeting Vector}

RNA and DNA were extracted from 11-285-14 hybridoma cells by TRIzol (Gibco-BRL). RNA was reverse transcribed to cDNA using the first-strand cDNA synthesis kit (Amersham Pharmacia Biotech). The homology regions were amplified by PCR using primers (Oswel) designed based on sequences available in GenBank and the MasterAmp High Fidelity Long PCR Kit (Epicentre Technologies). PCR products were prepared for cloning into the pKO-NTK vector (Stratagene) by digestion with compatible restriction enzymes (Pharmacia).

The 1.5-kb mouse constant gene was digested with BamHI and $E c o$ RI and the 2.2-kb intron fragment was digested with $B g / \mathrm{II}$ and HindIII. The 2.2-kb human constant gene was prepared for cloning next to the intron fragment by digestion with HindIII at the $5^{\prime}$ end and creating a blunt $3^{\prime}$ end by cutting with $S p H I$ and treating with Klenow enzyme. The second targeting vector, having the functionally rearranged VDJ region as the 5' homology region, was prepared in similar a way. The VDJ region was amplified by RT-PCR, sequenced and then digested with EcoRV and HindIII and cloned in frame to the human constant gene. Preparation and cloning were done according to standard procedures. Proper construction of the two vectors was confirmed by sequencing.

Chimaeric Antibody Development by Gene Targeting
Transfection of Hybridoma Cells and Selection of Homologous Recombinants

The targeting vector was linearized and transfected into 11-28524 hybridoma cells by electroporation at $0.23 \mathrm{kV}, 500 \mu \mathrm{F}$ at room temperature. The quantity of DNA used for transfection varied from 1 to $12 \mu \mathrm{g}$. Selection of recombinant cells was based on the activity of the positive selection marker (NEO) that confers resistance to G418, and the negative selection marker (TK) that confers resistance to ganciclovir (GANC). Optimal concentration of G418 was determined by titration $(0.5 \mathrm{mg} / \mathrm{ml})$. GANC was used at a concentration of $2 \mu M$. After electroporation, cells were cultured in bulk for 2 days then plated at $10^{5}$ cells/well in 24-well plates. Homologous recombinant cells were selected by 1 week of culture in G418 and 1 week in GANC. Supernatants were screened by enzyme-linked immunosorbent assay (ELISA) for secretion of the human isotype.

\section{Enzyme-Linked Immunosorbent Assay}

Plates were coated with $10 \mu \mathrm{g} / \mathrm{ml}$ of rabbit anti-human IgG (Dako), blocked with normal rabbit serum and 10\% fetal calf serum in carbonate, and the supernatants were added. Rabbit anti-human IgG conjugated to horseradish peroxidase (HRP; Dako), diluted $1 / 1,000$ in $10 \%$ fetal calf serum in PBS, was used as detection reagent. The signal was developed by addition of the substrate 2,2azino-di-3-ethyl benzothiazoline sulphonic acid that generates a coloured reaction product measured spectrophotometrically at $405 \mathrm{~nm}$. ELISA readings were compared to those obtained from 11-285-14 parent cell supernatants and human IgG1 standards. A positive result was operationally defined as a reading greater than the mean +2 standard deviations of the value obtained for parent cell supernatant tested in triplicate.

\section{Southern and Western Blots}

Southern blot experiments were performed by the alkali transfer method according to standard procedures. The human probe was labelled with alkaline phosphatase direct DNA probe labelling kit (Amersham Pharmacia Biotech) and used in conjunction with a chemiluminescent detection system. Western blot experiments were done according to standard procedures. Immunodetection was done using an anti-human Ig antibody conjugated to HRP (Dako) and ECL Plus Western blotting detection reagents (Amersham Biosciences). The molecular weight of the bands was determined according to a molecular weight marker curve, drawn using the Excel program.

\section{Results}

\section{Functionally Rearranged Allele}

To draw a complete picture of the 11-285-14 functionally rearranged heavy chain locus, the VDJ fragment was amplified by RT-PCR from 11-285-14 RNA, cloned into pGEMT vector and sequenced. Two different VDJ regions could be amplified using two degenerate primers that anneal to two different families of variable genes. The reverse primer was a degenerate primer that anneals to the beginning of the mouse constant $\gamma$ genes. This 
Fig. 1. Genomic situation of the functionally rearranged heavy chain locus in the hybridoma 11-285-14. Sw is the start of the switch region. Restriction sites: $\mathrm{B}=\mathrm{Bam} \mathrm{HI}$; $\mathrm{E}=E c o \mathrm{RI} ; \mathrm{H}=$ HindIII; $\mathrm{Bl}=$ BglII. Diagram is not drawn to scale.

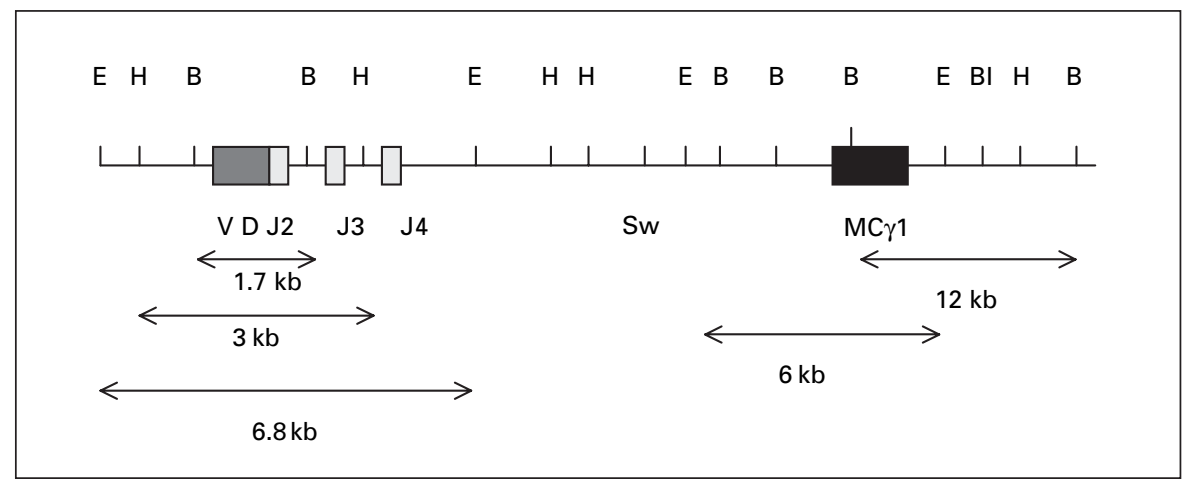

showed that 11-285-14 contained two variable genes that are rearranged, class switched to a constant $\gamma$ gene, transcribed and expressed at the mRNA level. The sequences of the two fragments were analysed using the International Immunogenetics Information System (http://imgt.cines.fr). One of the VDJ regions (V5) matched the IgHV5S12 of the Vh 7183 family of germ line genes in record U04228. Its diversity segment was identified as D-FL16.1, and its joining segment was identified as J2. V5 variable region was also found to be homologous to the mouse anti-CEA heavy chain variable gene published in GenBank (GenBank: gi 5708432). The other VDJ region matched the IgHV14S1 germ line variable gene. Its diversity region could not be identified and its joining segment matched in part J2. It partly matched J4 as well. A stop codon (TAG) was detected within its diversity region at amino acid number 105 . The presence of the stop codon along with the unclear picture of the diversity and $\mathrm{J}$ regions led to the consideration that V4 is the aberrant allele of 11-285-14 and V5 is the functionally rearranged allele. Based on these facts, the target Ig heavy chain locus was predicted to be as shown in figure 1 .

\section{Construction of Targeting Vectors}

A replacement vector was constructed to target the Ig heavy chain locus of the 11-285-14 hybridoma cells and to insert therein a human constant gene (fig. 2a). The 5' and $3^{\prime}$ homology regions were isogenic DNA fragments amplified by PCR and cloned into the $\mathrm{pKO}$ vector that had a positive-negative selection system built in. A positive selection marker (NEO) was placed between the two regions of homology; this confers resistance to G418 drug. A negative selection marker [herpes simplex virus thymidine kinase (HSV-TK)] was placed outside the region of homology; this gives the cells the ability to metabolize
GANC, leading to the formation of a toxic metabolite. Homologous recombination between the targeting vector and genomic DNA results in the loss of the HSV-TK sequences; such cells are selected by being resistant to G418 and GANC. On the other hand, non-homologous insertion of exogenous DNA into the genome results in the persistence of the HSV-TK sequence; such cells are resistant to G418 but sensitive to GANC. The targeting strategy is shown in figure $2 b$.

\section{Secretion of Chimaeric Antibody}

Forty-eight electroporation experiments were performed, which resulted in 4,370 resistant colonies. Eightyseven of these colonies showed secretion of the human isotype as determined by positive readings in ELISA (table 1). The level of the human isotype detected was in the range of $4-32 \mathrm{ng} / \mathrm{ml}$ of supernatant. Colonies in wells with positive readings were selected and cultured individually. Cells were left to grow to confluency between 3 and 7 days and a second ELISA test was performed. Some of these colonies continued to show positive ELISA readings, while others became negative. With continuous culturing, all colonies became negative in ELISA. Also, some of the resistant colonies died in long-term culture. All the clones initially identified as human isotype secretors continued to secrete the murine anti-CEA antibody.

\section{Integration of the Human $\gamma 1$ Gene by Homologous Recombination}

Representative clones were selected from transformants that had been identified as chimaeric antibody secretors by ELISA and lost secretion in continuous culture. Parent hybridoma cells were used as a negative control. A 500-bp fragment of the human constant gene could be amplified by PCR performed using DNA extracted from these clones (fig. 3a). To confirm the identity of the am- 
Fig. 2. Schematic diagrams of the targeting vector and the targeting strategy. a The targeting construct is a replacement vector that contains the human IgG1 constant gene $(\mathrm{HuC} \gamma 1)$ flanked by sequences homologous to the mouse $\mu$ intron at the left-hand side and sequences homologous to the mouse IgG1 constant gene at the right-hand side. Two selection markers, neomycin (NEO) and thymidine kinase (TK), are incorporated within the constructs to allow enrichment for the homologous recombinant cells. Arrows in the vector diagram indicate the primers used for sequencing. Restriction enzyme sites show the sites of linearization of the vector. b Targeting strategy for the development of a chimaeric antibody by targeting the mouse Ig heavy chain locus with the replacement vector. The predicted chimaeric situation at the 11-285-14 heavy chain locus induced by double cross-over at the homologous sequences is shown. The 6.4-kb BamHI fragment hybridizing to the human gene probe is diagnostic of integration at the correct place. The 11-kb Bg/II fragment is another diagnostic fragment. This picture applies for replacement events within the functional and the non-functional heavy chain alleles. The only difference is the distribution of the restriction sites before the VDJ regions. The non-functional VDJ lies within a 2.7-kb BamHI fragment instead of a 1.7-kb BamHI fragment for the functional allele.

Fig. 3. a Amplification of a fragment of the human $\gamma 1$ gene from DNA extracted from resistant transfectomas (lanes 2-4). The amplified product is a 500-bp fragment. Lane 1 is parent cell DNA used as a negative control. Lane 5 is the $100-b p$ ladder. b Southern blotting experiment using the human constant $\gamma 1$ gene as a probe. DNA was extracted from colonies that were initially positive in ELISA and had lost secretion after culture. DNA was digested with BamHI (gel 1). Lane 1 is parent cell DNA. Lane 2 is human white blood cell DNA showing the expected bands of 7.5 and 11 $\mathrm{kb}$ in size as calculated by analysing the sequence of the human Ig heavy chain locus available in GenBank. The expected 6.4-kb band indicating integration by homologous recombination was detected in sample No. 3 (lane 5). Additional bands of 9 and $14 \mathrm{~kb}$ were detected in the other samples possibly due to partial digestion or integration in other alleles. Gel 2 shows results of the same samples after cutting the DNA with Bg/II. The expected $11-\mathrm{kb}$ band is seen in sample No. 3 (lane 3).
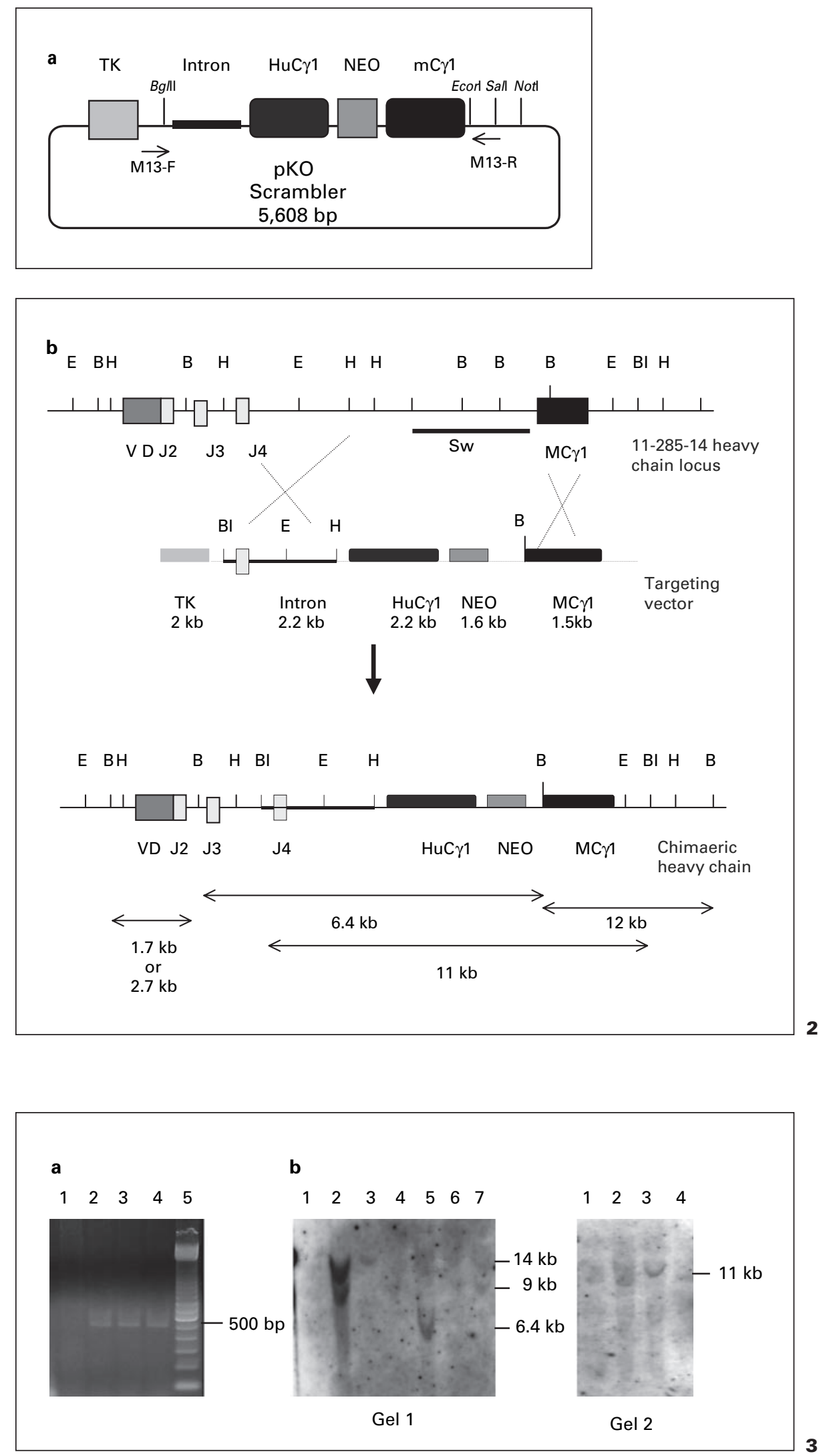


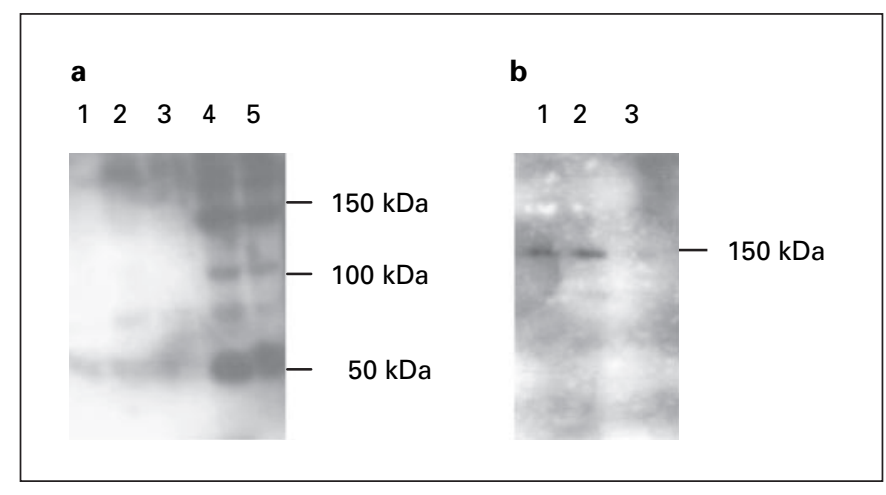

Fig. 4. Western blotting and immunodetection performed on protein extracted from resistant clones identified as chimaeric antibody secretors by ELISA. All samples were prepared under nonreducing conditions and run on non-reducing $0.5 \%$ SDS acrylamide gels. Immunodetection was done with HRP anti-human Ig (Dako). a Lane 1 is protein extracted from parent cells. Lanes $2-5$ are protein extracted from samples described above. $150 \mathrm{kDa}$ is the size of a completely assembled antibody, while $50 \mathrm{kDa}$ is the size of the human heavy chain; $100 \mathrm{kDa}$ is a heavy chain dimer. b The samples in lanes 1 and 2 were protein extracted from 12D1G7 colony that showed positive results in Southern blot experiment (fig. 3). This colony was plated by semi-limiting dilution and the subclones gave positive readings in second and third ELISAs. The sample in lane 3 in the same figure is protein extracted from a colony (12A1) that was positive in the first ELISA screening and lost the ability to grow in selection medium with continuous culture (cells have lost the NEO gene and most probably the human gene also); these cells were subsequently grown in normal medium in order to get enough cells for protein extraction.

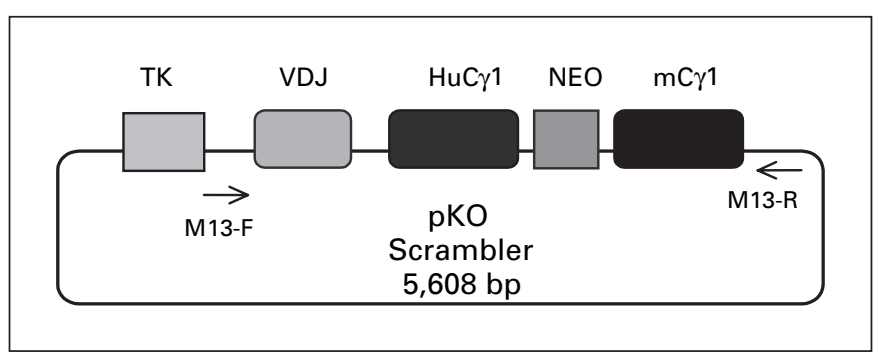

Fig. 5. Schematic diagram of the second targeting vector having the functionally rearranged VDJ region as the 5' homology region cloned in frame to the human constant gene.

plified DNA, the PCR product was sequenced (sequences not shown). The sequences obtained were compared to the human and mouse genomes using the GenBank Blast program. Comparison showed $100 \%$ homology with sequences on human chromosome 14 (human IgG) and no similarity with the mouse genome. According to the prediction, Southern blotting of DNA extracted from clones that had stopped secretion of the human isotype, after digestion with $B a m \mathrm{HI}$ or $B g l \mathrm{II}$, resulted in the detection of the expected 6.4-kb-sized and the 11-kb-sized fragments (fig. 2b) in one of the four representative transformants (fig. 3b). These results provide evidence that the human gene is still integrated within the heavy chain locus of this clone, even after losing secretion of the human isotype.

\section{Screening for the Presence of the Human Isotype Intracellularly}

The intracellular pool of the synthesized chimaeric heavy chains was investigated by Western blotting, performed on proteins extracted from the resistant colonies which were initially positive in ELISA. Most of these experiments gave negative results because by the time (almost 2 weeks) these colonies reached a sufficient number of cells to enable extraction of enough protein for the assay, they were losing the ability to secrete the human isotype. In two of the Western blot trials, the presence of the anticipated chimaeric antibody was shown (fig. 4a, b).

\section{Trials to Stabilize and Enhance Secretion of the \\ Chimaeric Antibody}

To increase the chance of targeting to the functional gene locus, a second targeting vector was constructed, which had the functionally rearranged VDJ region (V5) as the $5^{\prime}$ homology arm. This was cloned in frame with the human constant gene within the $\mathrm{pKO}$ vector that already had the mouse constant gene as the $3^{\prime}$ homology arm (fig. 5). The results of electroporations with this vector were similar to those with the intron vector (table 1). All the positive clones lost secretion of the human isotype within few weeks of the initial positive ELISA. Different linearization sites for the two targeting vectors were also tried but this did not affect or enhance the stability of secretion. Since methylation of the human transgene can be one of the reasons why colonies initially identified as secretors stop secreting the chimaeric antibody, the antimethylating agent - azacytidine - was used at a sublethal dose $(4 \mu M)$ to inhibit methylation. No effect on expression of the human isotype was detected. In another attempt to enhance the secretion of chimaeric antibody, cells were cultured in medium containing IL-6 $(1 \mathrm{ng} / \mathrm{ml})$ since it is one of the cytokines known to increase the secretion of antibodies in hybridomas. After 1 week of culture, the supernatants were tested by ELISA. No human isotype was detected. 
Table 1. Summary of electroporation experiments that resulted in secreting colonies

\begin{tabular}{|c|c|c|c|c|c|c|c|}
\hline Vector & $\begin{array}{l}\text { Quantity } \\
\text { of DNA } \\
\mu \mathrm{g}\end{array}$ & $\begin{array}{l}\text { Linearization } \\
\text { site }\end{array}$ & $\begin{array}{l}\text { Transfection } \\
\text { efficiency }^{\mathrm{a}}\end{array}$ & $\begin{array}{l}\text { Resistant } \\
\text { colonies }^{\mathrm{b}}\end{array}$ & $\begin{array}{l}\text { Positive } \\
\text { wells }^{\mathrm{c}}\end{array}$ & $\begin{array}{l}\text { Homologous } \\
\text { recombination } \\
\text { frequency }^{\mathrm{d}}\end{array}$ & $\begin{array}{l}\text { Absolute } \\
\text { frequency }\end{array}$ \\
\hline Intron & 1 & NotI & 45 & 45 & 3 & 6.6 & 1.5 \\
\hline Intron & 1 & NotI & 106 & 548 & 15 & 2.7 & 7.5 \\
\hline Intron & 2 & NotI & 150 & 580 & 10 & 1.7 & 5 \\
\hline Intron & 5 & $B g l \mathrm{II} / S a l \mathrm{I}$ & 19 & $187^{f}$ & 5 & 2.7 & 0.5 \\
\hline Intron & 5 & NotI/SalI & 10 & 115 & 2 & 1.7 & 0.2 \\
\hline Intron/VDJ & $2 / 2$ & NotI/SalI & 73 & 146 & 8 & 5.5 & 1.6 \\
\hline Intron & 2 & NotI & 100 & 209 & 11 & 5.3 & 2.2 \\
\hline Intron & 7 & $B g / \mathrm{II} / \mathrm{SalI}$ & 21 & $211^{\mathrm{f}}$ & 6 & 2.8 & 0.6 \\
\hline Intron & 5 & NotI & 12 & $116^{\mathrm{f}}$ & 14 & 12.0 & 1.4 \\
\hline VDJ & 6 & EcoRI & 39 & $390^{\mathrm{f}}$ & 13 & 3.3 & 1.3 \\
\hline $\begin{array}{l}{ }^{\mathrm{a}} \text { The nun } \\
{ }^{\mathrm{b}} \text { Total nu } \\
{ }^{\mathrm{c}} \text { Number } \\
{ }^{\mathrm{d}} \text { Homolc } \\
\text { colonies by } \mathrm{t} \\
\text { ony. } \\
{ }^{\mathrm{e}} \text { Absolut } \\
\text { lated by divi } \\
{ }^{\mathrm{f}} \text { Selectior }\end{array}$ & $\begin{array}{l}\text { G418-resi } \\
\text { of colonies } \\
\text { ls containi } \\
\text { combinati } \\
\text { number o } \\
\text { ency is an } \\
\text { e total nun } \\
\text { ith G418 }\end{array}$ & $\begin{array}{l}\text { ant colonies p } \\
\text { esistant to G4 } \\
\text { resistant colc } \\
\text { n frequency (p } \\
\text { G418 }{ }^{\mathrm{r}} \text { GANC } \\
\text { timate of hom } \\
\text { er of positive }\end{array}$ & $\begin{array}{l}10^{6} \text { plated cel } \\
\text { and GANC. } \\
\text { es with super } \\
\text { entage) was } \\
\text { lonies } \times 10 \text { (10us recomb } \\
\text { onies by the }\end{array}$ & $\begin{array}{l}\text { lculated b } \\
\text { Consideri } \\
\text { ation eve } \\
\text { amber of } t\end{array}$ & $\begin{array}{l}\text { lividing } \\
\text { one well } \\
\text { per } 10^{6} \\
\text { nsfected }\end{array}$ & $\begin{array}{l}\text { e total number } \\
\text { contains one se } \\
\text { ansfected cells } \times 10^{6} \text {. }\end{array}$ & $\begin{array}{l}\text { of positive } \\
\text { reting col- } \\
\text { It is calcu- }\end{array}$ \\
\hline
\end{tabular}

\section{Discussion}

The targeting vectors constructed to introduce the human constant $\gamma 1$ gene into the 11-285-14 heavy chain locus were replacement-type vectors (fig. 2, 5). Studies have revealed that chromososmal Ig $\mu$ genes modified by gene replacement (double reciprocal recombination) are expressed at wild-type levels, whereas those modified by vector integration (single reciprocal recombination) have lower levels of Ig $\mu$ gene expression [8]. Replacement vectors also resulted in a consistently higher frequency of homologous recombination than integration vectors with less variation between cell lines [9]. It is known that gene targeting with an integration vector yields a recombinant structure in which the introduced DNA is flanked by duplicate DNA segments. Secondary recombination between these duplicated homologous regions may occur and thus reverses the targeting. Recombinants with integration events in the Ig heavy chain locus were found to be especially unstable [10]. It has been shown that homologous recombination in hybridoma cells is similar to that observed in other mammalian cell types $\left(10^{-6}\right.$ recombinants/cell), while random recombination is greater than 1,000-fold more frequent, and most transfected cells are not even targeted [11]. The necessity for a selection sys- tem that enriches homologous recombinant cells and the possibility of application of the positive-negative selection system only to replacement vectors rendered this type of vector more acceptable than integration vectors. All of this suggested that gene replacement may be a preferred method for the construction of hybridomas producing chimaeric antibodies.

The design of the targeting vector was based on information available in the literature [9-12]. The 5' homology was chosen to be an isogenic DNA fragment of the mouse VDJ-C $\mu$ intron that contains the enhancer and the matrix attachment regions necessary to maintain stable expression of the constant genes [13]. The $3^{\prime}$ homology region was $1.5 \mathrm{~kb}$ of isogenic DNA from the mouse constant $\gamma 1$ gene. Since 11-285-14 hybridoma secretes anti-CEA antibody of IgG1 isotype, it was expected that the functional heavy chain gene locus (the target) is class switched to the constant $\gamma 1$ gene (fig. 1). The transgene was a $2.2-\mathrm{kb}$ fragment of the human constant gene that starts with the $3^{\prime}$ end of the intron before the $\mathrm{CH} 1$ exon and ends after the poly A termination signal. Therefore, production of the chimaeric antibody can only occur if the human constant gene is integrated downstream to an appropriate transcriptional promoter, translation initiation site, and splice donor sequence provided by the endogenous functionally 
rearranged variable gene segment. Positive reading in ELISA screening for secretion of the human isotype is indicative of integration of the human gene by homologous recombination within the Ig heavy chain locus.

The homologous recombination frequencies obtained in this study (table 1) were higher than those reported for other comparable integration vectors $(0.46 \%$ in Kardinal et al. [10] and 0.5\% in Mocikat et al. [6]) or replacement vectors $(0.35-1 \%$ in Yarnold and Fell [9]; 0.99-5.69\% in Kardinal et al. [12]) targeted to an isogenic Ig heavy chain locus. The reason may be the different cell line used in this study since it was shown that the efficiency of mediating homologous recombination process could vary significantly among cell lines [9]. Although the homologous recombination events were obtained at a high enough efficiency, the human isotype was expressed at low levels in the positive clones. This was indicated by the ELISA results showing a level of secretion in the range of 4$32 \mathrm{ng} / \mathrm{ml}$. The results in all the electroporations that gave positive clones followed the same pattern of initial positivity, followed by negative readings after subcloning. These results suggested that some changes were occurring in the cells during selection and cultivation.

The chromosomal IgH locus is a hot spot for intrachromosomal homologous recombination, promoted by the enhanced transcriptional activity and the recombinationally active chromatin environment within this locus [14]. The ability of most of the clones to grow normally in selection medium during long-term culture indicated that they still had the NEO gene. The stable integration of the human $\gamma 1$ gene was proved by PCR amplification of a 500 -bp fragment of the human gene from DNA from positive clones after long-term culture (2-3 months). Southern blot results provided evidence that the human gene remained within the heavy chain locus in some of the clones and was not excised out by secondary recombination, even after losing secretion. We cannot exclude the possibility that the human gene could be excised from some of these clones but not all of them during culture. The small proportion of cells still containing the human gene secrete the human isotype at a low level undetected by the ELISA used for screening. Also, it could be that DNA from these cells showed the diagnostic fragments with the human probe on Southern blotting. This low level of target gene (low number of cells still having the human gene) could explain the low intensity of bands obtained in Southern blot although a lot of DNA and a highly sensitive probe were used.

Fundamental understanding of changes during the processes of selection of recombinant clones and their adaptation to the subcloning growth environment is lacking. Some cells may undergo irreversible alteration at the genome level; some may exhibit changes in their gene expression pattern, while others may acquire modulation of various fluxes by changing nutrient/metabolite concentrations and enzyme activities [15]. Gene integration, transcription, translation, protein processing and the secretion apparatus all affect the expression level of a gene product. In antibody-producing cells in particular, stable productivity is a complex issue, since separate genes, which are regulated independently, encode heavy and light chains. Secretion of the mature antibody into the supernatant depends on accurate assembly of the chains in the endoplasmic reticulum [16].

Stability of gene expression in recombinant antibodyproducing cells is described by several groups with differing results; some reported stable expression while others reported loss of gene expression during long-term culture (summarized in Borth et al. [17]). Producers do convert to non-producers by genetic rearrangement, regulation of expression or improper posttranslational processing. Even at low conversion rates of producer to non-producer, the non-producer would have an inherent growth advantage, which would eventually cause them to outgrow the producers [18]. One group reported loss of heavy chain as the main cause of loss of antibody production and non-producing subclones appeared after only 2 weeks of culturing [19]. Others have reported a continuous decrease in light and heavy chain production during longterm culture without the appearance of a non-producing subpopulation. This indicated that the assembly in the endoplasmic reticulum is one of the major rate-limiting factors in antibody production [17]. It is worth noting that 11-285-14 hybridoma cells have shown high stability in long-term culture with loss of secretion occurring very infrequently. In addition, targeted clones that had lost secretion of the human isotype continued to secrete the mouse isotype after long-term culture.

Although there have been many reports on the production kinetics of mouse hybridoma and transfectoma cell lines [20-23], none, to our knowledge, has analysed the changes that may happen during the selection and adaptation process of gene-targeted hybridoma cells. The few published papers on production of chimaeric antibody by gene targeting showed this approach to be highly efficient [8-10]. The only problem reported in those studies, which dealt with interrupted secretion, was due to secondary recombination caused by duplication of sequences, since the targeting vectors used there were insertion vectors $[24,25]$. 
We report here our experience of using gene targeting for the development of a chimaeric version of the 11-28514 anti-CEA antibody. Although the homologous recombination efficiency obtained in this study was comparable and even better than in other similar studies, no clones producing chimaeric antibody at the wild-type level were obtained. This questions the efficiency of application of this method to all types of cell lines. We have used here replacement vectors and have shown that loss of the human transgene is not the cause of losing the human isotype secretion in all cases. Instability of secretion was not due to secondary recombination but to other yet undefined epigenetic or physiologic mechanisms that will form the basis of interesting areas of research for the future.

\section{Conclusion}

Gene targeting resulted in transformants with unstable and low production rates of chimaeric anti-CEA antibody.

\section{Acknowledgment}

This work was supported by the College of Graduate Studies and the Research Administration (grant No. MS 047), Kuwait University.

\section{References}

1 Glennie MJ, van de Winkel JGJ: Renaissance of cancer therapeutic antibodies. Drug Discov Today 2003;8:503-510.

2 Clark M: Antibody humanization: A case of the emperor's new clothes? Immunol Today 2000;21:397-402.

- 3 Ford CHJ, Bartlett SE, Casson AG, Marsden $\mathrm{CH}$, Gallant ME: Efficacy and specificity of vindesine monoclonal anti-carcinoembryonic antigen conjugates with nine human cancer cell lines. NCI Monogr 1987;3:107-116.

-4 Casson AG, Ford CHJ, Marsden CH, Gallant ME, Bartlett SE: Efficacy and selectivity of vindesine monoclonal anti-CEA antibody conjugates on human tumour cell lines grown as xenografts in nude mice. NCI Monogr 1987;3: 117-124.

-5 Ford CHJ, Osborne PA, Rego BG, Mathew A: Bispecific antibody targeting of doxorubicin to CEA-expressing colon cancer cell lines in vitro and in vivo. Int $\mathrm{J}$ Cancer 2001;92:851-855.

-6 Mocikat R, Kardinal C, Lang P, Zeidler R, Thierfelder S: Unaltered immunoglobulin expression in hybridoma cells modified by targeting of the heavy chain locus with an integration vector. Immunology 1995;84:159-163.

7 Kim JH, Bae SW, Hong HJ, Lee GM: Decreased chimaeric antibody productivity of $\mathrm{KR} 12 \mathrm{H}-1$ transfectoma during long-term culture results from decreased antibody gene copy number. Biotechnol Bioeng 1996;51:479487.

-8 Baker MD, Karn HA, Read LR: Restoration of a normal level of immunoglobulin production in a hybridoma cell line following modification of the chromosomal immunoglobulin $\mu$ gene by gene replacement. J Immunol Methods 1994; 168:25-32.
9 Yarnold S, Fell HP: Chimerization of antitumour antibodies via homologous recombination conversion vectors. Cancer Res 1994;54: 506-512.

10 Kardinal C, Hooijberg E, Lang P, Zeidler R, Mocikat R: Integration vectors for antibody chimerization by homologous recombination in hybridoma cells. Eur J Immunol 1995;25: 792-797.

11 Vasquez KM, Marburger K, Intody Z, Wilson $\mathrm{JH}$ : Manipulating the mammalian genome by homologous recombination. Proc Natl Acad Sci USA 2001;98:8403-8410.

12 Kardinal C, Selmayr M, Mocikat R: Genetic stability of gene targeted immunoglobulin loci. 1. Heavy chain isotype exchange induced by a universal gene replacement vector. Immunology 1996;89:309-315.

13 Ronai D, Berru M, Shulman MJ: Variegated expression of the endogenous immunoglobulin heavy-chain gene in the absence of the intronic locus control region. Mol Cell Biol 1999; 19: 7031-7040.

14 Raynard SJ, Read LR, Baker MD: Evidence for the murine IgH locus acting as a hot spot for intrachromosomal homologous recombination. J Immunol 2002;168:2332-2339.

15 Korke R, Rink A, Seow TK, Chung MCM, Beattie $\mathrm{CW}, \mathrm{Hu}$ WS: Genomic and proteomic perspectives in cell culture engineering. J Biotechnol 2002;94:73-92.

16 Strutzenberger K, Borth N, Kunert R, Steinfellner W, Katinger H: Changes during subclone development and ageing of human antibody-producing recombinant $\mathrm{CHO}$ cells. J Biotechnol 1999;69:215-226.

17 Borth N, Strutzenberger K, Kunert R, Steinfellner W, Katinger H: Analysis of changes during subclone development and ageing of human antibody-producing heterohybridoma cells by Northern blot and flow cytometry. J Biotechnol 1999;67:57-66.
18 Kromenaker SJ, Srienc F: Stability of producer hybridoma cell lines after sorting: A case study. Biotechnol Prog 1994;10:299-307.

19 Couture ML, Heath CA: Relationship between loss of heavy chains and the appearance of nonproducing hybridomas. Biotechnol Bioeng 1995; 47:270-275.

20 Petch D, Butler M: The effect of alternative carbohydrates on the growth and antibody production of a murine hybridoma. Appl Biochem Biotechnol 1996;59:93-104.

21 Miller WM, Blanch HW, Wilke CR: A kinetic analysis of hybridoma growth and metabolism in batch and continuous suspension culture: Effect of nutrient concentration, dilution rate, and pH. Biotechnol Bioeng 2000;67:853871

22 Lee MS, Lee GM: Hyperosmotic pressure enhances immunoglobulin transcription rates and secretion rates of KR12H-2 transfectoma. Biotechnol Bioeng 2000;68:260-268.

23 DeZengotita VM, Schmelzer AE, Miller WM: Characterization of hybridoma cell responses to elevated $\mathrm{pCO}(2)$ and osmolality: Intracellular $\mathrm{pH}$, cell size, apoptosis, and metabolism. Biotechnol Bioeng 2002;77:369-380.

24 Mocikat R, Kardinal C, Selmayr M: Genetic stability of gene-targeted immunoglobulin loci. 2 . Influence of the cell line and the vector linearization site. Mol Gen Genet 1997;256:499508.

25 Mocikat R: Improving the expression of chimaeric antibodies following homologous recombination in hybridoma cells. J Immunol Methods 1999;225:185-189. 